\title{
Factors contributing to therapeutic effects evaluated in acupuncture clinical trials
}

\author{
Guang-Xia Shi, Xiao-Min Yang, Cun-Zhi Liu ${ }^{*}$ and Lin-Peng Wang
}

\begin{abstract}
Acupuncture treatment has been widely used for many conditions, while results of the increasing numbers of randomized trials and systematic reviews remain controversial. Acupuncture is a complex intervention of both specific and non-specific factors associated with therapeutic benefit. Apart from needle insertion, issues such as needling sensation, psychological factors, acupoint specificity, acupuncture manipulation, and needle duration also have relevant influences on the therapeutic effects of acupuncture. Taking these factors into consideration would have considerable implications for the design and interpretation of clinical trials.
\end{abstract}

Keywords: Acupuncture, Clinical trial, Factors, Therapeutic effects

\section{Introduction}

Acupuncture is a core component in traditional Chinese medicine (TCM) and can be traced back more than 3000 years in China [1]. The World Health Organization endorses acupuncture for at least two dozen conditions [2]. The US National Institutes of Health issued a consensus statement proposing acupuncture as a therapeutic intervention for complementary medicine [3].

The randomized controlled trial (RCT) is considered the gold standard to provide evidence for a treatment's efficacy $[4,5]$. In recent years, there have been increasing numbers of RCTs showing that acupuncture was no more effective than sham acupuncture in migraine [6,7], low back pain $[8,9]$, and knee osteoarthritis [10,11], although both interventions were more effective than no treatment. Sham acupuncture includes needle insertion at non-acupuncture points, shallow needle insertion that does not penetrate below the skin (minimal or superficial needling), and blunt needles that touch, but do not penetrate the skin (placebo needling) [12].

The trial design comparing true and sham acupuncture presupposes that needling alone is the characteristic treatment element. However, acupuncture is a complex intervention of both specific and non-specific factors associated with therapeutic benefit. The lack of

\footnotetext{
* Correspondence: Icz623780@126.com

Acupuncture and Moxibustion Department, Beijing Hospital of Traditional Chinese Medicine affiliated to Capital Medical University, 23 Meishuguanhou Street, Dongcheng District, Beijing 100010, China
}

difference between real and sham acupuncture in RCTs may result from the omission of important components of acupuncture. As confounders in randomized designs, non-specific components of acupuncture maybe lead to false-negative results [13].

\section{Needling sensation}

Needling sensation is considered by many acupuncturists to be an important component of acupuncture since the early classical texts [14]. A key term that relates to needling sensation is Deqi [15], a composite of unique sensations interpreted as the flow of Qi or 'vital energy'. Based on the theory of TCM, acupuncture is successful only with the experience of Deqi, which suggests correct localization of the acupuncture point, and the arrival of Qi. This state is essential to acupuncture's therapeutic effect although few data are available [16,17]. The process of drawing Qi with needles is experienced by both patient and acupuncturist. Patients experience Deqi as multiple unique sensations at the needle site itself and around the site of needle manipulation, including soreness, aching, numbness, tingling, and even warmth [18]. Simultaneously, acupuncturists feel a change in the mechanical behavior of the tissues surrounding the needle (needle grasp). This change is described as tense, tight and full like 'a fish biting on a fishing line' as described in the literature [19]. Needle grasp is a biomechanical phenomenon of Deqi, which was characterized by an increase in the force necessary to pull the needle out of the tissue (pullout 
force) [20]. Langevin's trial supports connective tissue winding as the mechanism responsible for the increase in pullout force induced by needle rotation [21].

Experimental studies have found that Deqi sensation produces greater local blood flow at the needle site compared to simple needle insertion [22] and, the intensity of different acupuncture sensations are associated with subsequent analgesia. Kong et al. [23] found a similar relationship between acupuncture analgesia and numbness and soreness, but not for other sensations commonly associated with Deqi. A noticeable difference of therapeutic efficacy existed in some trials between acupuncture and sham acupuncture, in most cases because the latter did not involve manual stimulation and an attempt to induce Qi [24].

So far, the identification and investigation of these sensations have been widely ignored, mainly due to the lack of methodological consideration [25]. The sensory component of Deqi is difficult to study because of its subjective nature and it is influenced by many factors, such as the constitution of a patient, severity of the illness, location of the acupoints, and the needling techniques. There appears to be a limit to the number of sensations that can be discriminated by each individual patient [26]. A number of researchers have sought to establish a credible rating scale for Deqi, such as the McGill Pain Questionnaire [18,27], Subjective Acupuncture Sensation Scale [25], the Massachusetts General Hospital Acupuncture Sensation Scale [23], the Southampton Needle Sensation Questionnaire [28], and the 'Deqi composite' [29]. Although Deqi may have been traditionally intended to designate both the acupuncturist's and patient's perceptions [18], most of these scales have chosen to measure only one. Thus, existing measures of needling sensation are flawed and an improved questionnaire is essential to advance this area of research. Deqi should be taken into account in clinical trials and, further research is required to understand the underlying mechanisms [30].

\section{Psychological factors}

Expectancy, a crucial component of psychological factors, plays an important role in acupuncture practice $[31,32]$. Clinical experience suggests that patients receiving acupuncture have to expect to be treated. The insertion of needles for diagnostic reasons seldom seems to gain good effect. One possible basis for acupuncture effects might thus be changes in the direction of patients' attention. Positive expectation can significantly amplify acupuncture analgesia effects as evidenced by decreased subjective pain sensory rating as well as objective fMRI signal changes in response to calibrated noxious stimuli [33]. Diminished positive expectation appeared to inhibit acupuncture analgesia. Linde et al. [34] suggested that expectation of relief was the only factor that correctly predicted outcome, by reanalyzing results from several RCTs of acupuncture treatment for chronic pain. Patient's expectation and belief regarding a potentially beneficial treatment modulate activity in component areas of the reward system [32]. Negative cognition resulted in a change of the relationship between the pre-experimental expectancy of acupuncture and self-reported pain. The negative group produced an increased low-frequency component of heart rate variability (HRV) after acupuncture, whereas the positive group did not [25].

A systematic review revealed that there have been relatively few research studies assessing the relationship between expectancy and treatment responses following acupuncture, and suggested future studies should both manipulate and assess expectancy of patients [35]. It could be used as a stratification factor in clinical trials of acupuncture. Recently, a mixed-methods approach in a single report conducted by White et al. indicated that patients' beliefs about treatment veracity and confidence in outcomes were reciprocally linked, and this appears to shape how patients self-report outcome, complicating and confounding study interpretation [36].

In addition, psychological factors such as anxiety level should be considered as having an important influence on physiological response to acupuncture. It seems possible that the level of anxiety can modify HRV during acupuncture treatment and up to $40 \mathrm{~min}$ after the treatment [37]. A better understanding of the psychosocial factors involved in acupuncture should be able to improve outcomes for patients.

\section{Acupoint specificity}

According to the theory of TCM, acupoint specificity is the important basis of clarifying the functionality of acupoints and guiding acupuncture clinical practice. Classic theory recognizes about 361 points. All were said to be located on 14 main channels (or meridians) connecting the body in a web-like interconnecting matrix [38]. Traditionally, each acupuncture point has defined therapeutic actions. Questions about point specificity in acupuncture thus remain open. The selection and compatibility of acupoints are considered to have direct impact on the therapeutic effect. Data from neuroimaging studies in humans suggest that modulation of the limbic system may differentiate between specific and non-specific components of acupuncture [39].

\section{Acupuncture manipulation}

There are some methods of reinforcing-reducing manipulations of acupuncture in TCM, by slow and quick manipulation of needle, and manipulating the needle in cooperation with the patient's respiration. They are usually applied in combination [40]. All manipulations are based on the principle of puncturing along and 
against the flowing direction of the meridian Qi. Mastering the reinforcing-reducing manipulations of acupuncture will contribute to the improvement of therapeutic effects in clinical practice [41]. Differences of reinforcing and reducing acupuncture manipulations have different influences on the activities of natural killer cell, lymphokine-activated killer, and $\mathrm{T}$ lymphocyte subsets in peripheral blood of malignant tumor patients [42]. In addition, lifting-thrusting and twirling-rotating are different technical processes; both of them could promote the flow of $\mathrm{Qi}$, acting as reinforcement and reduction effects to a different extent. There are also variations in the direction, angle, and depth of needle insertion. With these factors combined, it is possible to affect the outcomes of acupuncture treatment $[43,44]$.

\section{Needle duration}

Needle duration refers to holding the needle in the acupoint after the use of needling manipulation, with the aim to wait for Qi arrival, regulate Qi circulation, eliminate pathogenic factors, and reinforce the antipathogenic Qi as well as the effect of manipulations. Different times of needle retention should be applied for different diseases [40].

Evidence from both human and animal studies has indicated that a striking feature of acupuncture analgesia is its longevity (a delayed onset), gradual peaking, and gradual returning [45]. For a typical 30-min acupuncture session, the pain threshold has a slowly increasing tendency even outlasting the treatment [46]. It is shown that the acesodyne effect could only be received when needle retention lasted for more than $20 \mathrm{~min}$ [47]. The effect of simple retention without manipulations for $15 \mathrm{~min}$ and 30 min were better than quick needling for $45 \mathrm{~min}$ in 289 cases of acute and chronic soft tissue injury [48]. The effect of $1 \mathrm{~h}$ of needle retention of body acupuncture might be better than $30 \mathrm{~min}$ in the cases of intractable hiccup [49]. Bao et al. observed the effect of $20 \mathrm{~min}$, $40 \mathrm{~min}$, and $60 \mathrm{~min}$ needle retention in the treatment of ischemic stroke, indicating there was a certain relation between retention duration and therapeutic effect. The longer the retention duration, the more significant the improvement detected on the myodynamia and hemorheology index [50]. However, quick needling could significantly relieve pain in systremma when compared to $30 \mathrm{~min}$ of needle retention [51]. Robust evidence of RCTs is needed to lend support for the effect of needle duration on acupuncture treatment.

\section{Other aspects}

All complex therapeutic interventions achieve their outcomes through a combination of specific and non-specific mechanisms [52]. It is important to emphasize that acupuncture is not a simple needling intervention.
Paterson and Dieppe argue for a more holistic experience in acupuncture than from needles alone [5]. Consistent with them, Kaptchuk contends that the therapeutic context for acupuncture depends not only on the specific therapeutic ritual applied but also on experiences, attitudes, and preferences of patients and providers, the patient-provider interaction, the setting, and the cultural background [15]. Previous trials that assessed the reliability of retractable type sham needling among acupuncturenave subjects or subjects with limited acupuncture experience revealed that patient's knowledge and experience of acupuncture also account for the different results $[53,54]$. Close interaction between patient and therapist is typical for acupuncture and will often involve suggestive components. There is evidence that the same acupuncture intervention can have quite different effects when provided in different contexts [55]. Factors related to therapeutic relationship, in particular patients' perceptions of that relationship, are likely to be important in facilitating good clinical outcomes [56]. Acupuncturists' skills, competence, and understanding of the TCM theory, lifestyle advice, and even individualized treatment protocols also play important roles in the therapeutic outcome [57-59].

In addition, the diagnostic process plays an important role in therapeutic outcome. The Western diagnosis is the theoretical basis for prescribing the drug and standardized administration of the drug follows, and therefore occurs before the intervention is started. TCM diagnosis, however, through questioning and examination, will be made during the first treatment session and will be reviewed and amended at each subsequent session. In acupuncture practice, during subsequent treatment sessions repeated pulse-taking and feedback about the effects of needle insertion are often varied to take into account any new concerns. Subsequently, this may result in a different therapeutic method [5].

\section{Conclusions}

In recent years, although there has been increasing evidence from large randomized trials and systematic reviews on the efficacy of acupuncture, the conclusions are controversial. The lack of difference between real and sham acupuncture in RCTs may result from the omission of important components of acupuncture. Assessing individual components will underestimate the true efficacy of acupuncture [36]. Apart from needle insertion, issues such as needling sensation, psychological factors, acupoint specificity, acupuncture manipulation, and needle duration also have relevant influences on the therapeutic effects of acupuncture. There may also be an interaction between different components within acupuncture treatment producing a clinical effect that is greater than the sum of its individual elements. Taking all these factors into consideration would have considerable 
implications for the design and interpretation of acupuncture clinical trials. Approaches such as factorial experiments, randomized pragmatic designs, and randomized cluster designs may be more appropriate and rigorous to sort out the complexity of acupuncture.

\section{Abbreviations}

TCM: Traditional Chinese medicine; RCT: Randomized controlled trial; HRV: Heart rate variability.

\section{Competing interests}

The authors declare that they have no competing interests.

\section{Acknowledgements}

The study was supported by Program for New Century Excellent Talents in University (NCET-09-0007),Technology New Star Program of Beijing (2009B46), and Major Scientific and Technological Research Projects of Beijing (D09050703550902)

\section{Authors' contributions}

SGX wrote and revised the manuscript; LCZ and WLP developed the original concepts for the review; YXM wrote the first draft of the paper. All authors contributed to the paper during development and read and approved the final version of the manuscript.

Received: 25 September 2011 Accepted: 21 April 2012

Published: 21 April 2012

\section{References}

1. Han JS, Ho YS: Global trends and performances of acupuncture research. Neurosci Biobehav Rev 2011, 35:680-687.

2. World Health Organization: Acupuncture: Review and Analysis of Reports on Controlled Clinical Trials. Geneva: WHO Library Cataloguing-in-Publication Data; 2002.

3. Bonafede $M$, Dick A, Noyes K, Klein JD, Brown T: The effect of acupuncture utilization on healthcare utilization. Med Care 2008, 46:41-48.

4. Devereaux PJ, Yusuf S: The evolution of the randomized controlled trial and its role in evidence-based decision making. J Intern Med 2003, 254:105-113.

5. Paterson C, Dieppe P: Characteristic and incidental (placebo) effects in complex interventions such as acupuncture. BMJ 2005, 330:1202-1205.

6. Linde K, Streng A, Jurgens S, Hoppe A, Brinkhaus B, Witt C, Wagenpfeil S, Pfaffenrath V, Hammes MG, Weidenhammer W, Willich SN, Melchart D: Acupuncture for patients with migraine: a randomized controlled trial. JAMA 2005, 293:2118-2125.

7. Diener HC, Kronfeld K, Boewing G, Lungenhausen M, Maier C, Molsberger A, Tegenthoff M, Trampisch HJ, Zenz M, Meinert R, GERAC Migraine Study Group: Efficacy of acupuncture for the prophylaxis of migraine, a multicentre randomized controlled clinical trial. Lancet Neurol 2006, 5:310-316.

8. Brinkhaus B, Witt CM, Jena S, Linde K, Streng A, Wagenpfeil S, Irnich D, Walther HU, Melchart D, Willich SN: Acupuncture in patients with chronic low back pain-a randomized controlled trial. Arch Intern Med 2006, 166:450-457.

9. Haake M, Müller HH, Schade-Brittinger C, Basler HD, Schäfer H, Maier C, Endres HG, Trampisch HJ, Molsberger A: German Acupuncture Trials (GERAC) for chronic low back pain: randomized, multicenter, blinded, parallel-group trial with 3 groups. Arch Intern Med 2007, 167:1892-1898.

10. Scharf HP, Mansmann U, Streitberger K, Witte S, Kramer J, Maier C, Trampisch HJ, Victor N: Acupuncture and knee osteoarthritis: a threearmed randomized trial. Ann Intern Med 2006, 145:12-20.

11. Witt CM, Jena S, Brinkaus B, Liecker B, Wegscheider K, Willich SN: Acupuncture in patients with osteoarthritis of the knee or hip. A randomized, controlled trial with an additional nonrandomized arm. Arthritis Rheum 2006, 54:3485-3493.

12. Lund I, Näslund J, Lundeberg T: Minimal acupuncture is not a valid placebo control in randomised controlled trials of acupuncture: a physiologist's perspective. Chin Med 2009, 4:1.
13. Lu $X$, Hongcai $S$, Jiaying $W$, Jing $H$, Jun $X$ : Assessing the quality of reports about randomized controlled trials of acupuncture treatment on mild cognitive impairment. PLoS One 2011, 6:e16922.

14. Kaptchuk TJ: The placebo effect in alternative medicine: can the performance of a healing ritual have clinical significance? Ann Intern Med 2002, 136:817-825

15. Asghar AU, Green G, Lythgoe MF, Lewith G, MacPherson H: Acupuncture needling sensation: the neural correlates of Deqi using fMRI. Brain Res 2010, 1315:111-118

16. MacPherson $H$, Green $G$, Nevado A, Lythgoe MF, Lewith $G$, Devlin $R$, Haselfoot R, Asghar AU: Brain imaging of acupuncture: comparing superficial with deep needling. Neurosci Lett 2008, 434:144-149.

17. Hui KK, Sporko TN, Vangel MG, Li M, Fang J, Lao L: Perception of Deqi by Chinese and American acupuncturists: a pilot survey. Chin Med 2011, 6:2.

18. Park H, Park J, Lee H, Lee H: Does Deqi (needle sensation) exist? Am J Chin Med 2002, 30:45-50.

19. Enblom A, Hammar M, Steineck G, Börjeson S: Can individuals identify if needling was performed with an acupuncture needle or a nonpenetrating sham needle? Complement Ther Med 2008, 16:288-294

20. Langevin HM, Churchill DL, Fox JR, Badger GJ, Garra BS, Krag MH: Biomechanical response to acupuncture needling in humans. J Appl Physiol 2001, 91:2471-2478.

21. Langevin HM, Churchill DL, Wu J, Badger GJ, Yandow JA, Fox JR, Krag MH: Evidence of connective tissue involvement in acupuncture. FASEB J 2002, 16:872-874

22. Napadow V, Dhond RP, Kim J, LaCount L, Vangel M, Harris RE, Kettner N, Park K: Brain encoding of acupuncture sensation--coupling on-line rating with fMRI. Neurolmage 2009, 47:1055-1065.

23. Kong J, Gollub R, Huang T, Polich G, Napadow V, Hui K, Vangel M, Rosen B, Kaptchuk TJ: Acupuncture de qi, from qualitative history to quantitative measurement. J Altern Complement Med 2007, 13:1059-1070.

24. Madsen MV, Gøtzsche PC, Hróbjartsson A: Acupuncture treatment for pain: systematic review of randomised clinical trials with acupuncture, placebo acupuncture, and no acupuncture groups. BMJ 2009, 338:a3115.

25. Kong J, Fufa DT, Gerber AJ, Rosman IS, Vangel MG, Gracely RH, Gollub RL Psychophysical outcomes from a randomized pilot study of manual, electro, and sham acupuncture treatment on experimentally induced thermal pain. J Pain 2005, 6:55-64.

26. Mao JJ, Farrar JT, Armstrong K, Donahue A, Ngo J, Bowman MA: De qi: Chinese acupuncture patients' experiences and beliefs regarding acupuncture needling sensation-an exploratory survey. Acupunct Med 2007, 25:158-165.

27. Vincent CA, Richardson PH, Black JJ, Pither CE: The significance of needle placement site in acupuncture. J Psychosom Res 1989, 33:489-496.

28. White P, Bishop F, Hardy H, Abdollahian S, White A, Park J, Kaptchuk TJ, Lewith GT: Southampton needle sensation questionnaire: development and validation of a measure to gauge acupuncture needle sensation. $J$ Altern Complement Med 2008, 14:373-379.

29. Hui KK, Nixon EE, Vangel MG, Liu J, Marina O, Napadow V, Hodge SM, Rosen BR, Makris N, Kennedy DN: Characterization of the "deqi" response in acupuncture. BMC Complement Altern Med 2007, 7:33.

30. Park J, Park H, Lee H, Lim S, Ahn K, Lee H: Deqi sensation between the acupuncture-experienced and the naïve: a Korean study II. Am J Chin Med 2005, 33:329-337.

31. Salih N, Bäumler PI, Simang M, Irnich D: Deqi sensations without cutaneous sensory input: results of an RCT. BMC Complement Altern Med 2010, 10:81

32. Pariente J, White P, Frackowiak RS, Lewith G: Expectancy and belief modulate the neuronal substrates of pain treated by acupuncture. Neurolmage 2005, 25:1161-1167.

33. Kong J, Kaptchuk TJ, Polich G, Kirsch I, Vangel M, Zyloney C, Rosen B, Gollub RL: An fMRI study on the interaction and dissociation between expectation of pain relief and acupuncture treatment. Neurolmage 2009, 47:1066-1076.

34. Linde K, Witt CM, Streng A, Weidenhammer W, Wagenpfeil S, Brinkhaus B, Willich SN, Melchart D: The impact of patient expectations on outcomes in four randomized controlled trials of acupuncture in patients with chronic pain. Pain 2007, 128:264-271.

35. Colagiuri B, Smith CA: A systematic review of the effect of expectancy on treatment responses to acupuncture. Evid Based Complement Alternat Med 2012, 2012:857-804 
36. White P, Bishop FL, Prescott P, Scott C, Little P, Lewith G: Practice, practitioner, or placebo? A multifactorial, mixed-methods randomized controlled trial of acupuncture. Pain 2012, 153:455-462.

37. Vickland V, Rogers C, Craig A, Tran Y: Anxiety as a factor influencing physiological effects of acupuncture. Complement Ther Clin Pract 2009, 15:124-128.

38. Zhao ZQ: Neural mechanism underlying acupuncture analgesia. Prog Neurobiol 2008, 85:355-375

39. Dhond RP, Kettner N, Napadow V: Do the neural correlates of acupuncture and placebo effects differ? Pain 2007, 128:8-12.

40. Cheng X: Chinese acupuncture and moxibustion. Beijing: Foreign Languages Press; 1999.

41. Qiu XH, Lu SK: Discussion on reinforcing-reducing manipulations of acupuncture in Internal Classic. Zhongguo Zhen Jiu 2009, 29:850-853.

42. Sun $H, Y u Y C, H e W$ : Influence of reinforcing and reducing acupuncture manipulations on the activities of natural killer cell, lymphokineactivated killer and T lymphocyte subset $s$ in peripheral blood of malignant tumor patients. Zhongguo Zhen Jiu 1992, 12:39-42.

43. Wang L, Jing MX, Zhi JM, LU J, Wang CY, Liu QG: Effects of reinforcing and reducing methods by twirling and rotating the needle on contents of CGRP and NO in rats with stress-induced hypertension. Zhongguo Zhen Jiu 2011, 31:337-341.

44. Fan GQ, Zhao Y, Fu ZH: Acupuncture analgesia and the direction, angle and depth of needle insertion. Zhongguo Zhen Jiu 2010, 30:965-968.

45. Price DD, Rafii A, Watkins LR, Buckingham B: A psychophysical analysis of acupuncture analgesia. Pain 1984, 19:27-42.

46. Bai L, Tian J, Zhong C, Xue T, You Y, Liu Z, Chen P, Gong Q, Ai L, Qin W, Dai $J$, Liu Y: Acupuncture modulates temporal neural responses in wide brain networks: evidence from fMRI study. Mol Pain 2010, 6:73.

47. Research gGroup of aAcupuncture aAnesthesia: Basic Research Department, Capital University of Medicine: Influence of acupuncture on feeling threshold of the skin. Chin Med 1993, 53:151-154.

48. Wang LX: Relation between needle retention duration and therapeutic effect on treatment of acute and chronic soft tissue injuries. Chin AcupMox 1996, 12:40-45.

49. He YZ, Han B, Hu J, Yuan L, Chen ZM, Li JM: Clinical observation on the treatment of ischemic apoplexy by different needling-retention times. New Tradit Chin Med 2005, 37:58-60.

50. Bao F, Liang Z, Wang FQ: Clinical observation on treatment of stubborn hiccup by acupuncture with different needle-retaining time. Zhongguo Zhen Jiu 2003, 23:21-22.

51. Lin SF, Ma PF, Wan HC, Liu WH, Bai YF: Treatment of 38 cases of systremma with quick needling of intensive stimulation. Zhongguo Zhen Jiu 2008, 28:176.

52. Araujo M: Does the choice of placebo determine the results of clinical studies on acupuncture. Res Complement Med 1998, 5:8-11.

53. Park J, White A, Stevinson C, Ernst E, James M: Validating a new nonpenetrating sham acupuncture device: two randomized controlled trials. Acupunct Med 2002, 20:168-174.

54. White P, Lewith $G$, Hopwood V, Prescott P: The placebo needle, is it a valid and convincing placebo for use in acupuncture trials? A randomised, single-blind, cross-over pilot trial. Pain 2003, 106:401-409.

55. Kaptchuk TJ, Kelley JM, Conboy LA, Davis RB, Kerr CE, Jacobson EE, Kirsch I, Schyner RN, Nam BH, Nguyen LT, Park M, Rivers AL, McManus C, Kokkotou E, Drossman DA, Goldman P, Lembo AJ: Components of placebo effect: randomised controlled trial in patients with irritable bowel syndrome. BMJ 2008, 336:999-1003.

56. Bishop FL, Lewith GT: A review of psychosocial predictors of treatment outcomes: what factors might determine the clinical success of acupuncture for pain? J Acupunct Meridian Stud 2008, 1:1-12

57. MacPherson $H$, Thomas K: Self-help advice as a process integral to traditional acupuncture care: implications for trial design. Complement Ther Med 2008, 16:101-106

58. MacPherson $H$, Thorpe $L$, Thomas K: Beyond needling-therapeutic processes in acupuncture care: a qualitative study nested within a lowback pain trial. J Altern Complement Med 2006, 12:873-880.

59. Liu T: Role of acupuncturist in acupuncture treatment. Evid Based Complement Alternat Med 2007, 4:3-6. doi:10.1186/1745-6215-13-42

Cite this article as: Shi et al:: Factors contributing to therapeutic effects evaluated in acupuncture clinical trials. Trials 2012 13:42.

\section{Submit your next manuscript to BioMed Central and take full advantage of:}

- Convenient online submission

- Thorough peer review

- No space constraints or color figure charges

- Immediate publication on acceptance

- Inclusion in PubMed, CAS, Scopus and Google Scholar

- Research which is freely available for redistribution

Submit your manuscript at www.biomedcentral.com/submit
C) Biomed Central 